\title{
EFFECTS OF PROLONGED RUNNING PERFORMED AT THE INTENSITY CORRESPONDING TO THE ONSET OF BLOOD LACTATE ACCUMULATION, ON MAXIMUM ISOKINETIC STRENGTH IN ACTIVE NON-ATHLETIC INDIVIDUALS
}

\author{
Denadai BS ${ }^{1}$, Greco CC ${ }^{1}$, Tufik $\mathrm{S}^{2}$ e Mello MT ${ }^{2}$ \\ ${ }^{1}$ Laboratório de Avaliação da Performance Humana, Departamento de Educação Física, Instituto de Biociências de \\ Rio Claro, Universidade Estadual Paulista Júlio de Mesquita Filho, Rio Claro, SP - Brasil \\ ${ }^{2}$ Departamento de Psicobiologia e Instituto do Sono, Universidade Federal de São Paulo, São Paulo, SP - Brasil \\ Correspondência para: Benedito Sérgio Denadai, Laboratório de Avaliação da Performance Humana, Departamento de \\ Educação Física, Instituto de Biociências de Rio Claro, UNESP, Av. 24 A, 1515, Bela Vista, CEP 13506-900, Rio Claro, \\ SP - Brasil, e-mail: bdenadai@rc.unesp.br
}

Recebido: 23/10/2006 - Revisado: 28/02/2007 - Aceito: 03/05/2007

\begin{abstract}
Objective: The objective of this study was to analyze the effects of prolonged continuous running performed at the intensity corresponding to the onset of blood lactate accumulation (OBLA), on the peak torque of the knee extensors, analyzed in relation to different types of contraction and movement velocities in active individuals. Method: Eight men $(23.4 \pm 2.1$ years; 75.8 $\pm 8.7 \mathrm{~kg} ; 171.1 \pm 4.5 \mathrm{~cm}$ ) participated in this study. First, the subjects performed an incremental test until volitional exhaustion to determine the velocity corresponding to OBLA. Then, the subjects returned to the laboratory on two occasions, separated by at least seven days, to perform five maximal isokinetic contractions of the knee extensors at two angular velocities (60 and $180^{\circ} . \mathrm{s}^{-1}$ ) under eccentric and concentric conditions. Eccentric peak torque (EPT) and Concentric peak torque (CPT) were measured at each velocity. One session was performed after a standardized warm-up period ( 5 min at $50 \% \mathrm{VO}_{2}$ max). The other session was performed after continuous running at OBLA until volitional exhaustion. These sessions were conducted in random order. Results: There was a significant reduction in CPT only at $60^{\circ} . \mathrm{s}^{-1}(259.0 \pm 46.4$ and $244.0 \pm 41.4$ N.m). However, the reduction in EPT was significant at $60^{\circ} . \mathrm{s}^{-1}(337.3 \pm 43.2$ and $321.7 \pm 60.0 \mathrm{~N} . \mathrm{m})$ and $180^{\circ} . \mathrm{s}^{-1}(346.1 \pm 38.0$ and $319.7 \pm 43.6 \mathrm{~N} . \mathrm{m})$. The relative strength losses after the running exercise were significant different between contraction types only at $180^{\circ} . \mathrm{s}^{-1}$. Conclusion: We can conclude that, in active individuals, the reduction in peak torque after prolonged continuous running at OBLA may be dependent on the type of contraction and angular velocity.
\end{abstract}

Key words: concentric; eccentric; angular velocity; aerobic exercise; fatigue.

\section{RESUMO}

\section{Efeitos da corrida prolongada realizada na intensidade correspondente ao início do acúmulo do lactato no sangue na força máxima isocinética em indivíduos ativos não atletas}

Objetivo: O objetivo deste estudo foi analisar os efeitos da corrida contínua prolongada realizada na intensidade correspondente ao início do acúmulo do lactato no sangue (OBLA) sobre o torque máximo dos extensores do joelho analisado em diferentes tipos de contração e velocidade de movimento em indivíduos ativos. Método: Oito indivíduos do gênero masculino (23,4 $\pm 2,1$ anos; 75,8 \pm 8,7 kg; 171,1 \pm 4,5 cm) participaram deste estudo. Primeiramente, os sujeitos realizaram um teste incremental até a exaustão voluntária para determinar a velocidade correspondente ao OBLA. Posteriormente, os sujeitos retornaram ao laboratório em duas ocasiões, separadas por pelo menos sete dias, para realizar 5 contrações isocinéticas máximas para os extensores do joelho em duas velocidades angulares (60 e $\left.180^{\circ} \cdot \mathrm{s}^{-1}\right)$ sob as condições excêntrica (PTE) e concêntrica (PTC). Uma sessão foi realizada após um período de aquecimento padronizado (5 min a $50 \% \mathrm{VO}_{2} \max$ ). A outra sessão foi realizada após uma corrida contínua no OBLA até a exaustão voluntária. Essas sessões foram executadas em ordem randômica. Resultados: Houve redução significante do PTC somente a $60^{\circ} \cdot \mathrm{s}^{-1}(259,0 \pm 46,4$ e 244,0 \pm 41,4 N.m). Entretanto, a redução do PTE foi significante a $60^{\circ} \cdot \mathrm{s}^{-1}\left(337,3 \pm 43,2\right.$ e 321,7 \pm 60,0 N.m) e $180^{\circ} \cdot \mathrm{s}^{-1}$ (346,1 \pm 38,0 e 319,7 \pm 43,6 N.m). As reduções relativas da força após o exercício de corrida foram significantemente diferentes entre os tipos de contração somente a $180^{\circ} \cdot \mathrm{s}^{-1}$. Conclusão: Podemos concluir que, em indivíduos ativos, a redução no torque máximo após uma corrida contínua prolongada no OBLA pode ser dependente do tipo de contração e da velocidade angular.

Palavras-chave: concêntrica; excêntrica; velocidade angular; exercício aeróbio; fadiga. 


\section{INTRODUCTION}

Muscle fatigue can be defined as a reduction in the maximal force-generating capacity ${ }^{1-3}$. It is well known that impairment of performance resulting from muscle fatigue differs according to the types of contraction involved, the muscle groups tested, and the exercise duration and intensity. Specifically, exercises that contain a large eccentric component (for example, running) seem to promote greater strength loss after exercise, probably because of the muscle damage generated by this type of contraction ${ }^{4}$.

Some studies have used isokinetic dynamometry to investigate whether strength loss after running events is dependent on the muscle action that is being performed (i.e., isometric, concentric or eccentric) and the angular velocity of movement. Reductions in maximal concentric and eccentric muscle torque of knee extensors have been found following prolonged running events (2-8 h) of moderate intensity (55-75\% $\left.\mathrm{VO}_{2} \max \right)^{5-7}$. Lepers et al. ${ }^{5}$ showed that, following a two-hour run, strength losses under eccentric conditions were $6-7 \%$ greater than under concentric conditions. However, the reduced neural input to the vastus lateralis and vastus medialis, which is partially responsible for the reduction in force production, was not different between the eccentric and concentric conditions. Therefore, Lepers et al. ${ }^{5}$ suggested that the greater loss during the eccentric contraction type could be partially explained by ultrastructural muscle damage.

Compared with low-intensity events, high-intensity running requires activation of larger motor units with increased recruitment of glycolytic-oxidative muscle fibers, and increased intensity of the chemical processes in the muscle $^{8}$. However, few studies have investigated the alterations in neuromuscular function after shorter-duration events (20-60 min). Moreover, the studies that found decreases in the maximal strength-generating capacity of the knee extensor muscles following aerobic exercise only analyzed highly trained endurance runners. It is important to note that a prior period of eccentric training reduces the strength loss, soreness and elevated CK activity that are commonly observed after a bout of eccentric exercise ${ }^{9,10}$. Therefore, it is possible to hypothesize that the effects of aerobic running exercise on the strength loss may be different between trained and non-trained individuals.

The use of multiple conditioning components to address both neuromuscular strength and cardiovascular health has become an important part of most recommended exercise regimens. However, it has been shown previously that combined strength and endurance training may lead to lower strength/power muscle gains ${ }^{11}$. In this context, it may be important to analyze the possible influences of high-intensity running events on the neuromuscular function of sedentary and active individuals, with the aim of optimizing the effects of concurrent training (aerobic and strength training) and rehabilitation in this population. Therefore, the objective of this study was to analyze the effects of prolonged continuous running at the level of the onset of blood lactate accumulation (OBLA), on the peak muscle torque of the knee extensors for two types of contraction at different angular velocities in active non-athletic individuals.

\section{MATERIAL AND METHODS}

\section{Subjects}

Eight men who were physically active but not specifically trained volunteered to participate in the study. The subjects had the following characteristics [mean (SD)]: age 23.4 (2.1) years; mass 75.8 (8.7) kg; and height 171.1 (4.5) cm. All the subjects were healthy and free of cardiovascular, respiratory or neuromuscular diseases. A previous physical examination (including EKG) ensured that each participant was in good health. None of the subjects were smokers or were taking any medications. All the subjects gave their informed consent and the protocol had been approved by the university's ethics committee (No. 425/06). The subjects were instructed to arrive at the laboratory in a rested and fully hydrated state, at least two hours after their last meal, and to avoid strenuous exercise during the 48 hours preceding the test sessions. Each subject was tested at the same time of day (9:30 a.m. \pm 1:00 h), to minimize the effects of diurnal biological variation.

\section{Experimental design}

One week after the recruitment process, each subject was required to attend two laboratory familiarization sessions to lessen any learning effect during the subsequent strength testing. During these sessions, each participant completed five eccentric and concentric contractions for knee extensors on a Biodex isokinetic dynamometer (Biodex System 3, Biodex Medical Systems, Shirley, NY, USA) at two velocities (60 and $180^{\circ} \cdot \mathrm{s}^{-1}$ ). On the third visit to the laboratory, the subjects performed an incremental treadmill test until volitional exhaustion, to determine the maximal oxygen uptake $\left(\mathrm{VO}_{2} \mathrm{max}\right)$, the velocity associated with achieving $\mathrm{VO}_{2} \max$ ( $\mathrm{vVO}_{2} \mathrm{max}$ ), and the velocity at the onset of blood lactate accumulation (OBLA). After this test, the subjects returned to the laboratory on two occasions, separated by at least seven days, to perform maximal isokinetic knee contractions at each angular velocity (60 and $180^{\circ} . \mathrm{s}^{-1}$ ) under eccentric and concentric conditions. One session was performed after a standardized warm-up period ( $5 \mathrm{~min}$ at $50 \% \mathrm{VO}_{2} \max$ ). The other session was performed 15 min after continuous running at OBLA until volitional exhaustion. 


\section{Procedures}

Determination of $\mathrm{VO}_{2}$ max, $\mathrm{VVO}_{2}$ max and OBLA

$\mathrm{VO}_{2} \max , \mathrm{VVO}_{2} \max$ and OBLA were measured using an incremental protocol performed on a motorized treadmill (LIFE FITNESS 9800, Schiller Park, IL, USA) with the gradient set at $1 \%$. The initial speed was set at $7 \mathrm{~km} . \mathrm{h}^{-1}$ for $3 \mathrm{~min}$ and was then incremented by $1 \mathrm{~km} \cdot \mathrm{h}^{-1}$ every $3 \mathrm{~min}$, until voluntary exhaustion [mean $( \pm \mathrm{SD})$ time to exhaustion $=24.6 \pm 2.1$ $\mathrm{min}$. All stages of the incremental test were followed by a 30-sec period of rest. During this period, an earlobe capillary blood sample was collected. Throughout the tests, pulmonary gas exchange was determined breath-to-breath (SENSOR MEDICS - MMC, Anaheim, CA, USA). Before each test, the $\mathrm{O}_{2}$ and $\mathrm{CO}_{2}$ analysis systems were calibrated using ambient air and a gas of known $\mathrm{O}_{2}$ and $\mathrm{CO}_{2}$ concentrations, in accordance with the manufacturer's instructions. Heart rate (HR) was also monitored throughout the tests (Polar, Kempele, Finland). The breath-to-breath data were smoothed using a five-step moving average filter, from which rolling 15- sec averages were calculated. Earlobe capillary blood samples (25 $\mu \mathrm{l})$ were collected into a glass tube and were analyzed for lactate concentration using an automated analyzer (YSI 2300, Ohio, USA). $\mathrm{VO}_{2}$ max was defined as the highest 15 -sec $\mathrm{VO}_{2}$ value reached during the incremental test. All the subjects fulfilled at least two of the following three criteria for $\left.\mathrm{VO}_{2} \max : 1\right)$ respiratory exchange ratio $(\mathrm{R})$ greater than 1.1 ; 2) blood lactate concentration greater than $8 \mathrm{mM}$; and 3) peak HR at least equal to $90 \%$ of the age-predicted maximum $^{12}$. The $\mathrm{vVO}_{2} \max$ was defined as the minimum velocity at which $\mathrm{VO}_{2}$ max occurred ${ }^{13}$. OBLA was determined by linear interpolation, taking a fixed lactate concentration of $3.5 \mathrm{mM}^{14}$.

\section{Isokinetic testing}

A System 3 Biodex isokinetic dynamometer (Biodex Medical Systems Inc., Shirley, N.Y.) was used to measure peak torque (PT). The isokinetic dynamometer was calibrated prior to each testing session, in accordance with the procedures prescribed by the manufacturer. The subjects were placed in a sitting position, securely strapped into the test chair. Two crossover shoulder harnesses and one abdominal belt limited movements of the upper body. The trunk/thigh angle was $90^{\circ}$. The axis of the dynamometer was lined up with the right knee flexion-extension axis, and the lever arm was attached to the shank ( $2 \mathrm{~cm}$ above the lateral malleolus of the ankle) by a strap. During eccentric testing, each subject maximally resisted the downward movement of the lever arm through the full range of motion. Conversely, during concentric testing, each subject extended his right knee as forcefully as possible through the full range of motion. After the warm-up period (three submaximal and one maximal repetition at both speeds in the concentric and eccentric modes), the subjects performed five maximal isokinetic contractions of the knee extensors at each angular velocity (60 and $180^{\circ} . \mathrm{s}^{-1}$ ) under eccentric and concentric conditions presented in a random order (starting position corresponded to thigh/shank angle of $90^{\circ}$; range of motion was $90^{\circ}$; full extension $=0^{\circ}$ ). The concentric peak torque (CPT) and eccentric peak torque (EPT) were the highest torque values produced from five individual efforts.

\section{Running exercise}

All subjects were asked to run until volitional exhaustion on a treadmill at a speed corresponding to OBLA. Blood lactate levels were measured at the $10^{\text {th }}$ and $30^{\text {th }}$ minutes and at exhaustion.

\section{Statistical analyses}

The normality of the data was checked using the ShapiroWilk test. Peak torque for a given angular velocity was compared between the non-fatigued and fatigued states using the two-tailed Student's paired t test. Relative torque loss after the running exercise at similar angular velocities was compared between eccentric and concentric actions using the Wilcoxon test. The significance level was set at $\mathrm{p} \leq 0.05$.

\section{RESULTS}

The maximal and submaximal variables obtained during the incremental running tests are presented in Table 1.

Table 1. Maximal oxygen uptake $\left(\mathrm{VO}_{2} \max \right)$, velocity at $\mathrm{VO}_{2} \max$ $\left(\mathrm{vVO}_{2} \mathrm{max}\right)$ and velocity at onset of blood lactate accumulation expressed as absolute (OBLA) and relative values (\%OBLA). $\mathrm{N}=8$.

\begin{tabular}{ccccc}
\hline & $\begin{array}{c}\mathbf{V O}_{2} \max \\
\left(\mathbf{m l . k g}^{-1} \cdot \mathbf{m i n}^{-\mathbf{1}}\right)\end{array}$ & $\begin{array}{c}\mathbf{v V O}_{2} \mathbf{m a x} \\
\left(\mathbf{k m}^{-\mathbf{1}}\right)\end{array}$ & $\begin{array}{c}\text { OBLA } \\
\left(\mathbf{k m}^{-\mathbf{1}}\right)\end{array}$ & $\begin{array}{c}\text { \%OBLA } \\
\left(\% \text { VO }_{2} \mathbf{m a x}\right)\end{array}$ \\
\hline Mean \pm SD & $50.8 \pm 8.6$ & $14.2 \pm 0.7$ & $9.8 \pm 1.1$ & $73.1 \pm 5.4$ \\
\hline
\end{tabular}

The time to exhaustion at OBLA (tlim OBLA) was 56.4 $\pm 17.4 \mathrm{~min}$. The blood lactate response during submaximal running exercise is presented in Figure 1.

The mean values of CPT and EPT at different angular velocities, in the non-fatigued and fatigued states are presented in Figure 2. There was a significant reduction in CPT at an angular velocity of $60^{\circ} . \mathrm{s}^{-1}$. In addition, the reduction in EPT was significant at both 60 and $180^{\circ} . \mathrm{s}^{-1}$.

The relative decreases in muscle torque after the running exercise were significantly different between contraction types only at $180^{\circ} . \mathrm{s}^{-1}$ (Figure 3 ).

\section{DISCUSSION}

To our knowledge, this study is the first to examine the effects of prolonged continuous running at OBLA on the CPT and EPT at different angular velocities in active individuals. 


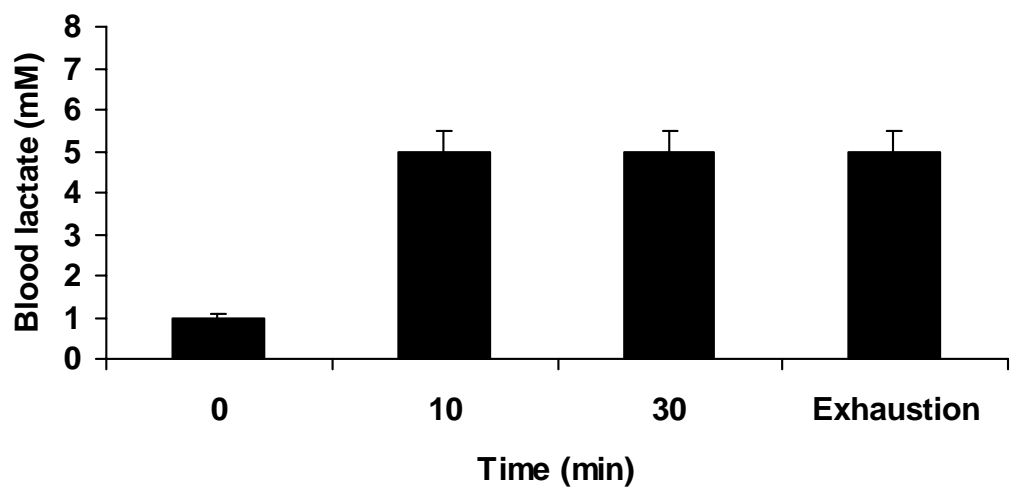

Figure 1. Blood lactate response during submaximal running exercise. $\mathrm{N}=8$.

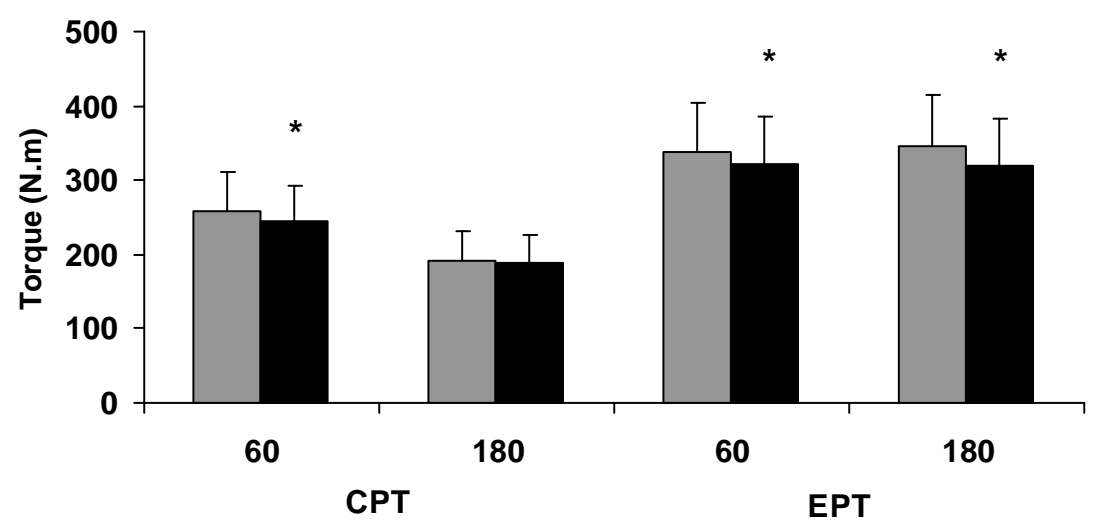

\section{$\square$ Non-fatigued $\square$ Fatigued}

* $\mathrm{P}<0.05$ in relation to non-fatigued state at same angular velocity.

Figure 2. Mean \pm SD values of concentric (CPT) and eccentric peak torque (EPT) at different angular velocities, in the non-fatigued and fatigued state. $\mathrm{N}=8$.

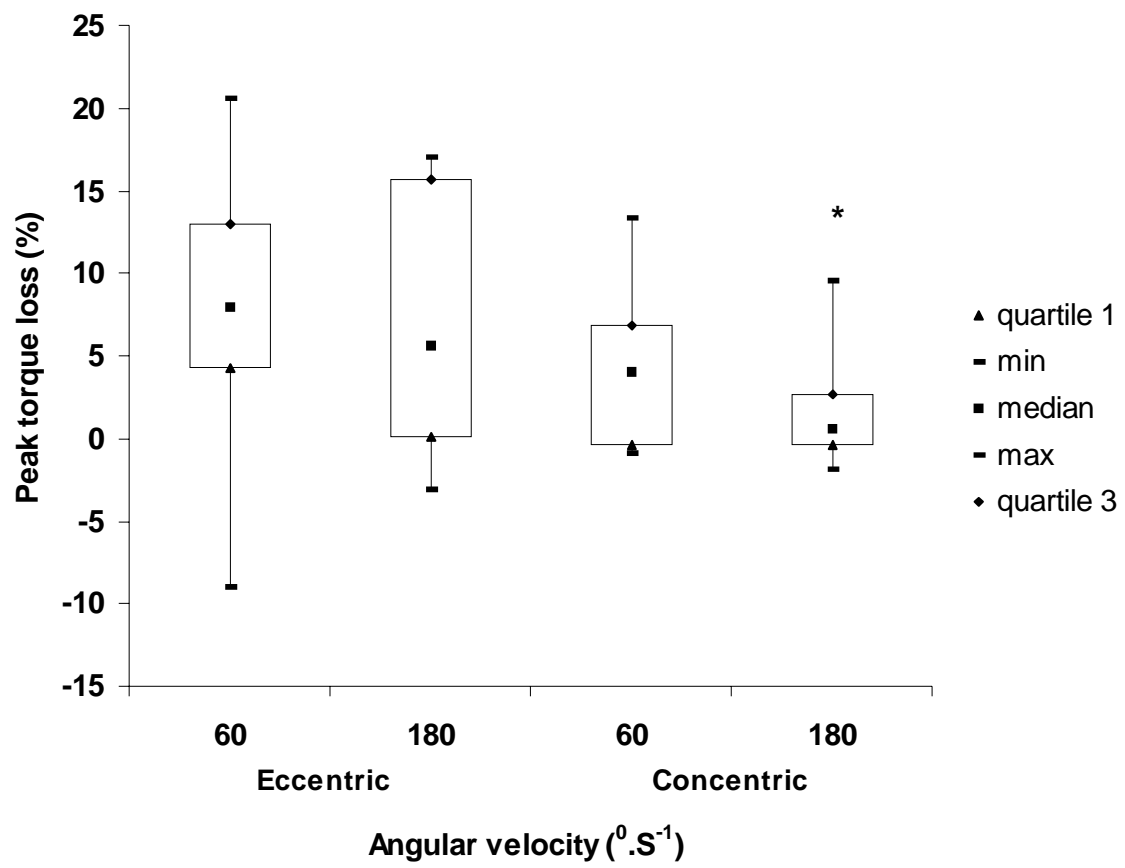

* $\mathrm{P}<0.05$ in relation to eccentric condition at same angular velocity.

Figure 3. Relative decreases in muscle torque after the running exercise. $\mathrm{N}=8$. 
Our main finding was that the strength loss resulting from prolonged continuous running at OBLA was dependent on the contraction type (i.e., concentric versus eccentric) and the angular velocity of movement (i.e., 60 versus $180^{\circ} . \mathrm{s}^{-1}$ ).

Among the possible mechanisms that may explain the fatigue generated by aerobic exercise are increases in $\mathrm{Ca}^{++}$ and metabolites (lactate, $\mathrm{H}^{+}$and ammonia), depletion of substrate (glycogen and creatine phosphate), presence of hypoglycemia, reduced neural input (excitability, firing rate of motor unit discharge and neuromuscular transmission) and ultrastructural muscle damage ${ }^{15,16}$. Some studies have found that fatigue following prolonged continuous running at OBLA (6 km) is mainly due to peripheral mechanisms (i.e., impairment of excitation-contraction coupling $)^{8}$. On the other hand, in prolonged activities (> 2 hours), central fatigue may also be involved, particularly at the spinal level ${ }^{4}$. Based on these data, it is possible to hypothesize that the strength loss found in our study can be explained mainly due to peripheral mechanisms.

The strength loss found in our study during concentric actions at $60^{\circ} \cdot \mathrm{s}^{-1}(7.4 \%)$ is apparently lower than what was found by Glace et al. ${ }^{7}$ and Lepers et al. ${ }^{5}$, who reported decreases of 18 and $14 \%$ in knee extension strength at $60^{\circ} \cdot \mathrm{s}^{-1}$ after running for two hours at $70-75 \% \mathrm{VO}_{2} \max$, respectively. Moreover, Sherman et al. ${ }^{6}$ found higher strength loss (35\% at $\left.60^{\circ} \cdot \mathrm{s}^{-1}\right)$ after running a marathon ( 3 hours). Thus, our data seem to support the hypothesis proposed by Lepers et al. ${ }^{5}$ that the relative strength loss during concentric actions is dependent on the duration of the running exercise. However, in our study there was no significant strength loss during concentric contractions at $180^{\circ} . \mathrm{s}^{-1}$. During muscle isokinetic contractions performed at high angular velocities, there is a predominant recruitment of type IIa and IIb fibers ${ }^{17}$. On the other hand, during submaximal exercise $\left(<\mathrm{VO}_{2}\right.$ max $)$ of medium duration (30-60 min), the type IIb fibers are less recruited ${ }^{18}$. Therefore, it is possible that the exercise duration and lower recruitment of type II fibers during high-intensity running exercise (tlim OBLA) determine lower relative strength loss during concentric contractions performed at high angular velocities. It is important to note that comparison between our data and the literature must be made with caution, since exercise intensity and aerobic status training may modulate the effects of aerobic exercise on strength loss.

Lepers et al. ${ }^{5}$ found that the decreases in muscle torque at 60 and $120^{\circ} . \mathrm{s}^{-1}$ after running for two hours at $75 \% \mathrm{VO}_{2} \max$ were greater under eccentric (18-21\%) than under concentric (13-14\%) conditions. Many authors have hypothesized that strength loss after repeated eccentric contractions, which characterize long-distance running, may depend on damage to the contractile apparatus. Since these morphological disturbances are found preferentially in type II fibers ${ }^{19}$, Lepers et al. ${ }^{5}$ pointed out that greater eccentric strength loss appears not to be due to a reduction in neural input but, rather, to a failure of the contractile mechanism, particularly in fast-twitch fibers. Our data partially support this hypothesis, since we found that strength loss was greater during eccentric than during concentric contraction only at $180^{\circ} . \mathrm{s}^{-1}$, at which fasttwitch fibers are preferentially recruited ${ }^{20}$. Since the muscle damage is time-dependent ${ }^{21}$, the shorter duration of aerobic exercise in our study may explain these apparently contradictory data. It is important to note that, differently from the concentric mode, there is no reduction in eccentric muscle torque with increased angular velocity ${ }^{22}$. Under these conditions (high angular velocity + high torque levels), even with lower muscle damage, aerobic running exercise of medium duration seems to determine higher fatigue during eccentric contraction.

We can conclude that, in active non-athletic individuals, the reduction in peak torque after prolonged continuous running at OBLA may be dependent on the contraction type and angular velocity. Therefore, it is possible to hypothesize that training and rehabilitation protocols similar to the experimental conditions of this study (i.e., aerobic + strength exercise in the same session performed by active individuals) may give rise to lower neuromuscular adaptations, particularly when the strength exercises are performed with low angular velocities and/or eccentric muscle contractions.

\section{REFERENCES}

1. Nicol C, Komi PV, Marconnet P. Fatigue effects of marathon running on neuromuscular performance. I Changes in muscle force and stiffness characteristics. Scand J Med Sci Sports. 1991;1:10-7.

2. Sahlin K, Seger JY. Effects of prolonged exercise on the contractile properties of human quadriceps muscle. Eur J Appl Physiol. 1995;71:180-6.

3. Forsberg A, Tesch P, Karlsson J. Effect of prolonged exercise on muscle strength performance. In: Asmussen E, Jorgensen K, editors. Biomechanics VI[A]. Baltimore: University Park Press; 1979. 62-7.

4. Millet GY, Lepers R. Alteration of neuromuscular function after prolonged running, cycling and skiing exercise. Sports Med. 2004;34:105-16.

5. Lepers R, Pousson M, Maffiuletti NA, Martin A, Van Hoecke J. The effects of a prolonged running exercise on strength characteristics. Int J Sports Med. 2000;21(4):275-80.

6. Sherman WM, Armstrong LE, Murray TM, Hagerman FC, Costill DL, Staron RC, et al. Effect of a 42.2-km footrace and subsequent rest or exercise on muscular strength and work capacity. J Appl Physiol. 1984;57(6):1668-73.

7. Glace BW, McHugh MP, Gleim GW. Effects of a 2-hour run on metabolic economy and lower extremity strength in men and women. JOSPT. 1998;27:189-96.

8. Skof B, Strojnik V. Neuromuscular fatigue and recovery dynamics following prolonged continuous run at anaerobic threshold. $\mathrm{Br}$ J Sports Med. 2006;40:219-22. 
9. Byrnes WC, Clarkson PM, White JS, Hsieh SS, Frykman PN, Maughan RJ. Delayed onset muscle soreness following repeated bouts of downhill running. J Appl Physiol. 1985;59:710-5.

10. Jones DA, Newham DJ. The effect of training on human muscle pain and damage. J Physiol. 1986;365:76.

11. Kraemer WJ, Patton JF, Gordon SE, Harman EA, Deschenes MR, Reynolds K, et al. Compatibility of high-intensity strength and endurance training on hormonal and skeletal muscle adaptations. J Appl Physiol. 1995;78:976-89.

12. Taylor HL, Buskirk ER, Henschel A. Maximal oxygen intake as an objective measure of cardiorespiratory performance. J Appl Physiol. 1955;8:73-80.

13. Caputo F, Denadai BS. Effects of aerobic endurance training status and specificity on oxygen uptake kinetics during maximal exercise. Eur J Appl Physiol. 2004;93:87-95.

14. Denadai BS, Gomide EB, Greco CC. The relationship between onset of blood lactate accumulation, critical velocity, and maximal lactate steady state in soccer players. J Strength Cond Res. 2005;19:364-8.

15. Green, H.J. Manifestations and sites of neuromuscular fatigue. In: Taylor AW, Gollnick PD, Green HJ, Ianuzzo CD, Noble EG, Metivier G, et al. Biochemistry of Exercise VII. Champaign (IL): Human Kinetics; 1990. p. 13-35.
16. Leveritt M, Maclaughlin H, Abernethy PJ. Changes in leg strength 8 and 32 h after endurance exercise. J Sports Sci. 2000;18:86571.

17. Paddon-Jones D, Leveritti M, Lonergan A, Abernethy $\mathrm{P}$. Adaptation to chronic eccentric exercise in human: The influence of contraction velocity. Eur J Appl Physiol. 2001;85:466-71.

18. Brooks GA, Mercier J. Balance of carbohydrate and lipid utilization during exercise: the "crossover" concept. J Appl Physiol. 1994;76:2253-61.

19. Friden J, Sjöstrom M, Ekblom B. Myofibrillar damage following intense eccentric exercise in man. Int J Sports Med. 1983;4: 170-6.

20. Farthing JP, Chilibeck PD. The effects of eccentric and concentric training at different velocities on muscle hypertrophy. Eur J Appl Physiol. 2003;89:578-86.

21. Kyröläinen H, Pullinen T, Candau R, Avela J, Huttunen P, Komi PV. Effects of marathon running on running economy and kinematics. Eur J Appl Physiol. 2000;82:297-304.

22. Yeadon MR, King MA, Wilson C. Modelling the maximum voluntary joint torque/angular velocity relationship in human movement. J Biomech. 2006;39:476-82. 